\title{
Reisen nach Südamerika
}

Am 10. und 11. März 2017 findet im Rahmen der Internationalen Tourismusbörse ITB Berlin das 18. Forum Reisen und Gesundheit des CRM Centrum für Reisemedizin statt. Die Fortbildungsveranstaltung für Ärzte und Apotheker befasst sich 2017 schwerpunktmäßig mit dem Thema „Gesundheitsvorsorge bei Reisen nach Südamerika“.
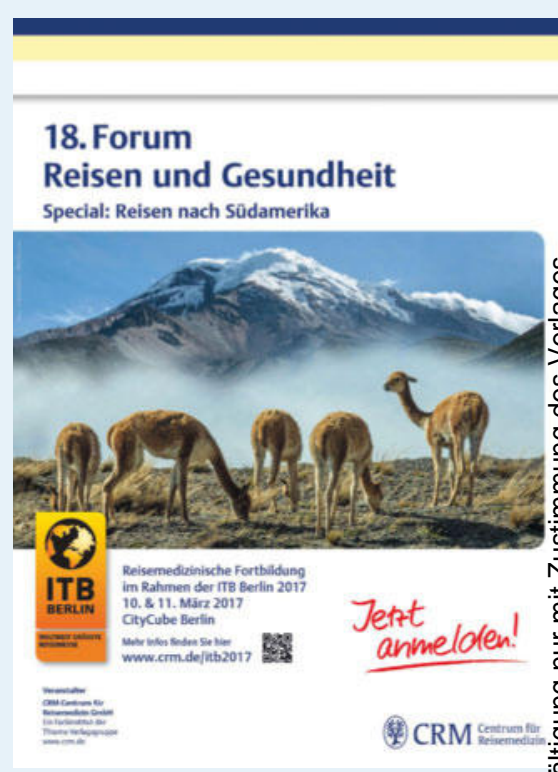

Infektionsrisiken in Südamerika: Zika, Dengue, Chagas

Der aktuelle Zikaausbruch in Süd- und Mittelamerika hat de Fokus von Medien, Öffentlichkeit und Wissenschaft noch einฮ mal verstärkt auf das Problem der von mückenübertragene $\frac{\mathbb{\Phi}}{1}$

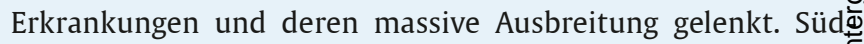
und Mittelamerika verzeichnen seit Jahren hohe Fallzahlen vo allem von Dengue- und Chikungunyafieber. Aktuelle Erkennt nisse und Entwicklungen auf dem Gebiet der Arbovirosen sin deshalb ein wichtiges Thema des Forums. Zunehmend für Aufơ merksamkeit sorgt auch die durch Raubwanzen übertragen® Chagaskrankheit. Die Infektion ist ausschließlich im lateinameథ rikanischen Raum endemisch, wird aber aufgrund von Migra tion immer häufiger auch in Europa und in den USA registrierto

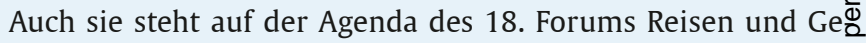
sundheit.

Update Weltseuchenlage und Impfungen

Neben Vorträgen, die sich speziell mit Infektionsrisiken in Süd amerika befassen und dabei auch Fallbeispiele von Reiserück kehrern vorstellen, wird das Forum außerdem allgemeine, häufi ge Themen der Reisemedizin aufgreifen: Was gehört in die Basisapotheke für Reisende? Welche dermatologischen Probleme् treten bei Reisen häufig auf und wie lassen sie sich verhindern: Wie lässt sich der Import unangenehmer „Souvenirs“ wie Wanzen, Flöhe oder Milben vermeiden?

Zudem erwartet die Teilnehmer ein Überblick der aktuellen Weltseuchenlage sowie ein Update zur Malariaprophylaxe und den Reiseimpfungen.

Das 18. Forum Reisen und Gesundheit des CRM Centrum für Reisemedizin findet am 10. und 11. März 2017 im Rahmen der Internationalen Tourismusbörse ITB im CityCube Berlin statt. Die Tagungsgebühr beträgt 225 Euro und beinhaltet einen Gutschein für die Internationale Tourismus Börse ITB. Informationen und Anmeldung unter www.crm.de.

Quelle: CRM Centrum für Reisemedizin, Düsseldorf 